\title{
Bioenergy recovery analysis from various waste substrates by employing a novel industrial scale AD plant
}

\author{
Rizwan Rasheed (Da , Abdullah Yasar ${ }^{\mathrm{a}}$, Sajid Rashid Ahmad (ob, Amtul Bari \\ Tabinda $^{\mathrm{a}}$, Saboor Ahmad Khan ${ }^{\mathrm{C}}$, and Yuehong Su ${ }^{\mathrm{d}}$ \\ aSustainable Development Study Centre, GC University Lahore, Pakistan; bDepartment of Architecture and Built \\ Environment, University of Nottingham, UK; ' Registrar Office, GC University Lahore, Pakistan; \\ ${ }^{\mathrm{d} C o l l e g e}$ of Earth and Environmental Sciences, University of Punjab, Lahore, Pakistan
}

\begin{abstract}
In this novel industrial scale case study, the bioenergy recovery based on sole and mixed cow-buffalo (CBM) and potato waste (PW) substrates has been analyzed in real time, i.e., on-site on a full-scale operational anaerobic digestion (AD) plant. The plant employed in this study is a novel design, consisting of tri-digesters connected via an underground UASB type lagoon allowing it to function as a continuous-flow reactor. The system has been further equipped with CSTR, microwave heating, gas scrubbers, compression, and storage systems. The highest energy recovery readings were $123.9 \mathrm{~m}^{3} / 1,000 \mathrm{~kg}, 77 \mathrm{~m}^{3} / 1,000 \mathrm{~kg}$, and $151.6 \mathrm{kWh} / 1,000 \mathrm{~kg}$ in terms of biogas, bio-methane, and electricity generated, respectively, with 75:25 ratio of CBM:PW. Operating with $100 \%$ CBM, yields of $79.9 \mathrm{~m}^{3} / 1,000 \mathrm{~kg}, 47 \mathrm{~m}^{3}$ / $1,000 \mathrm{~kg}$, and $95 \mathrm{kWh} / 1,000 \mathrm{~kg}$ were obtained. The percentage of recovery in bio-methane production increased on using the mixed substrates, but it was the lowest with a 25:75 ratio of CBM:PW. The electrical power generation efficiency was found to be significantly increased, but not distinctively with the plant aggregate power rating that was probably associated with the variable quality of biogas which was fed to the power generator. A linear regression analysis had shown a significant and positive correlation between the rate of VS removal and biogas yield.
\end{abstract}

\section{KEYWORDS}

Anaerobic digestion (AD); bioenergy; Pakistan; sustainable energy; waste-toenergy recovery

\section{Introduction}

Anaerobic digestion (AD) has been proven to be an efficient and profitable technique for the treatment and conversion of organic wastes into energy; likewise, many lab-scale experiments have shown that co-digested organic substrates give more efficient comparative outputs of bioenergy (Esposito et al. 2012). However, the transition from laboratory experiments to pilot and industrial scale in the alternate energy sector is tedious and costly. The extrapolation of labscale results to a pilot scale and commercially operable AD plant often leads to deceiving results (Weiland 2010). The reasons for such failures are mostly the different operating conditions and the use of synthetic feedstock (Hosseini and Wahid 2013). These problems lead the authors to invest in a sophisticated medium industrial scale AD plant, which is more practical, convenient, and realistic R\&D so to validate the results and advance more readily toward the commercialindustrial scale bioenergy generation (Song et al. 2014). In such a novel pilot scale, realistic operational conditions can be corrected on a daily basis (Hosseini et al. 2013), using online monitoring measurements (too expensive for labscale) and using real quantities and qualities of 
feedstock substrates, by providing realistic design parameters (Budzianowski 2012). As far as the performance and energy recovery from various feedstock substrates for an AD bioenergy system are concerned, it had been observed that many substrates such as fruit-vegetable wastes were digested rapidly and easily, whereas animal manure takes a longer time. In fruit/vegetable feedstock substrates, the lower TS, higher VS, and richer carbohydrate amounts present undergo a faster stage of hydrolysis which leads to an acidification stage, causing the inhibition of biogas generation (Baeyens et al. 2016; Gunaseelan 2004). Animal manures on the contrary, such as cow-buffalo dung, are abundant and easily and economically accessible. Moreover, they also provide other complementary advantages in terms of efficiency and effectiveness through their Supply chain, waste and odor management, etc. (Yang and Chen 2014). Many lab-scale studies had shown more efficiencies in terms of methane when animal manure was co-digested with other substrates such as food waste (Cuetos et al. 2011; Wang et al. 2013a, 2013b; Zhang et al. 2013; Kothari et al. 2014; Fitamo et al. 2016). In experimental studies, several tests were performed on various ratios of cattle manure $(\mathrm{CM})$ to food waste $(\mathrm{FW})$ so to verify the increased amount of methane with respect to various ratios, particle size, and rate of organics load. Where these had been evident that with a ratio of 2:1 of CM to FW, decreasing the FW particle size and controlling loading rate at $3 \mathrm{~g} \mathrm{VS} / \mathrm{L} / \mathrm{d}$, respectively; the methane recovery had been increased sufficiently (Agyeman and Tao 2014; Zhang et al. 2013a). Few other studies (Abouelenien et al. 2014; Sawasdee and Pisutpaisal 2014; Sittijunda 2015) described that agricultural wastes such as Napier grass, cassava waste, coconut waste, coffee been grounds with semi-solid chicken manure, and Napier grass with slaughterhouse waste, respectively, were co-digested at thermophilic and mesophilic temperatures, while utilization of fresh chicken manure enhanced the bioenergy recovery efficiency up to $93 \%$ compared to the control, whereas in second process the treated chicken manure was used that increased the amount of methane production up to $42 \%$ than the control. Several studies have highlighted that there are many contributing factors for an effective yield of commercialindustrial scale bioenergy recovery efficiency and enrichment such as suitable and available feedstock, effective co-digestion, and hydraulic retention time. Whereas pretreatment of substrates, their composition, and operational conditions such as temperature, $\mathrm{pH}$, and design and size of the digester employed also play a vital role in enhanced recovery of biogas (Alatriste-Mondragón et al. 2006; Astals, Nolla-Ardèvol, and Mata-Alvarez 2012; Callaghan et al. 2002; Cavinato et al. 2010; Comino, Riggio, and Rosso 2012; Hinken et al. 2008; Nkemka and Murto 2010; Park and Li 2012; Pobeheim et al. 2010; Shah et al. 2015). Apart from these some researches, Akbulut (2012) and Gebrezgabher et al. (2010) also highlighted that the power proficiency of a bioenergy plant could be variable and reliant upon the power rating of the generation set. Walla and Schneeberger (2008) also showed similar facts based on their study of various 25-2,500 kW bioenergy plants; larger-scale bioenergy plants showed an increase in their relevant electrical-power efficiency. However, the major aspect that seems missing in all such earlier studies is the determination of energy productivity on a full-scale industrial plant in real time, i.e., on commercial-industrial scale plant, according to realistic operational conditions. Therefore, the objective of the current research was to monitor and investigate the energy recovery in terms of biogas and electric power based on a $150 \mathrm{kVA}$ generator from a mediumlarge-scale bioenergy plant (Figure 1) designed and installed at an industrial area near Lahore, Pakistan. Various mass ratios of feedstock substrates, i.e., cow and buffalo manure (CBM) versus potato waste $(\mathrm{PW})$, were employed for this particular study.

\section{Methodology}

\section{Determination of substrates and energy recovery}

The ultimate aim of a bioenergy plant design is to maximize the methane yield based on the feedstock and the size of the plant. At this specific medium-large-scale bioenergy plant, the typical 


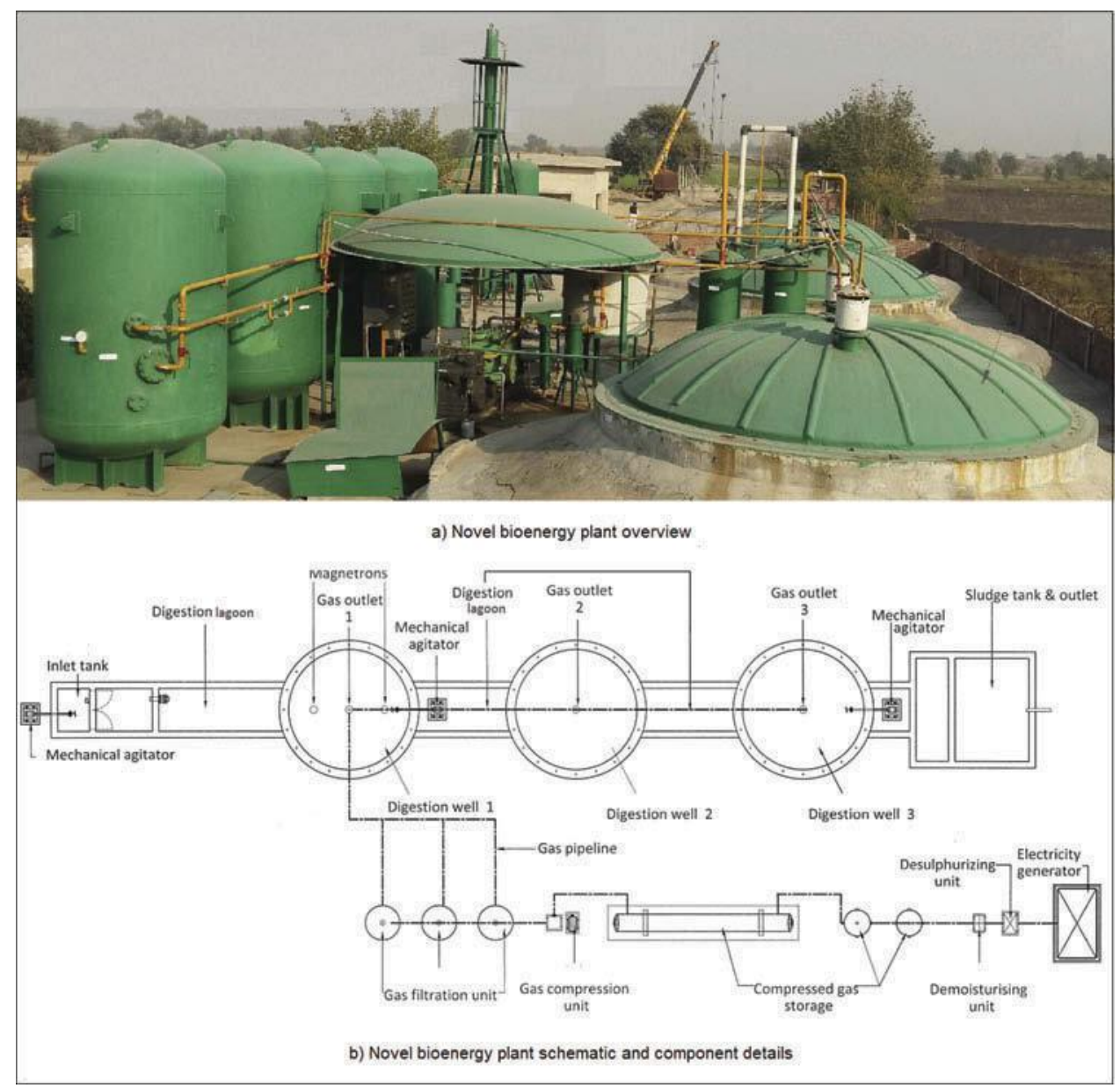

Figure 1. Novel industrial bioenergy plant installed at an industrial area near Lahore, Pakistan.

experiments for bioenergy recovery analysis have been performed for about a year with conveniently and economically available substrates, i.e., CBM and its mixture with PW in various ratios.

\section{Substrate characterization}

The AD process energy analysis experiments at the plant were performed with five substrate ratios of CBM and PW i.e., 100:00; 50:50; 75:25; 25:75, and 00:100. To attain the best bioenergy productivity and recovery, the effective operational parameters such as $\mathrm{pH}$, temperature, water content, and continuous stirring were monitored and maintained within the optimum ranges. The subsequent substrate slurry samples were collected and analyzed by the lab at SDSC, GC University Lahore for determining the TS, VS, and C/N ratio as per standard methodology (Apha 1998; ECOFYS 2005). Table 1 presents all the parameters of the experiments and analysis, as also presented in references (Deublein and Steinhauser 2011; Moody et al. 2011). The COD of the relevant substrate slurries was also determined at the beginning and end of each month as per standard method-8000 using a spectrometer.

\section{Monitoring of energy output}

The capability of the plant for feedstock substrate handling was recorded as $24,000 \mathrm{~kg}$. Firstly $20,000 \mathrm{~kg}$ of $100 \%$ CBM substrate was employed and fed to the plant that was left for 30 days to acclimatize the system. Subsequently, a further feedstock at the rate of 4,000 kg/day has been applied. To assure anaerobic 
Table 1. Feedstocksubstrates' characteristics in various mixtures of cow-buffalo manure (CBM) and potato waste (PW) used in the experiments at a novel industrial scale bioenergy plant.

\begin{tabular}{lcccccc}
\hline $\begin{array}{l}\text { CBM:PW } \\
\text { (ratios) }\end{array}$ & Wet weight (kg:kg) & TS wet basis (\% avg.) & VS dry basis. (\% avg.) & $\begin{array}{c}\text { C/N } \\
\text { Ratio }\end{array}$ & $\begin{array}{c}\text { Temperature }\left({ }^{\circ} \mathrm{C}\right. \\
\text { avg.) }\end{array}$ & $\begin{array}{c}\mathrm{pH} \\
\text { (avg.) }\end{array}$ \\
\hline $100: 00$ & $24,000: 00$ & 12 & 84 & 11.80 & 35.2 & 7.3 \\
$75: 25$ & $18,000: 6000$ & 11.25 & 86.75 & 15.54 & 35.8 & 6.9 \\
$50: 50$ & $12,000: 12,000$ & 10.5 & 89.5 & 19.27 & 36.1 & 6.6 \\
$25: 75$ & $6000: 18,000$ & 9.75 & 92.25 & 23.01 & 36.9 & 6.5 \\
$00: 100$ & $00: 24,000$ & 9 & 95 & 26.75 & 35.3 & 6.9 \\
\hline
\end{tabular}

conditions at an optimal mesophilic temperature condition $\left(35-37^{\circ} \mathrm{C}\right)$ and $\mathrm{pH}$, microwave irradiations 105 were employed in digestion well 1 for about 5-10 min intervals, i.e., after the induction of each 1,000 $\mathrm{kg}$ of fresh substrate against a total of $4,000 \mathrm{~kg}$ of substrate that was introduced daily into the reactor. To control the quality and stability of the AD reactor, the $\mathrm{pH}$ level of each treatment was measured after every 3 days by the installed $\mathrm{pH}$ probes. Similar practices were observed for all feedstock substrate ratios experimented. The cumulative energy output monitoring was performed over a period of 10 months from July 2015 till 110 April 2016. The energy outputs have been examined and recorded in terms of mean biogas yields in $\mathrm{m}^{3} /$ month and then further converted to electrical power $(\mathrm{kWh} / \mathrm{month})$. Identical biogas bioenergy amounts had been generated by employing dairy manure, as previously used (Kryvoruchko et al. 2009; Li et al. 2015). The monitored results are tabulated in Table 2.

\section{Analysis of bioenergy yield}

The generated biogas was stored in the biogas storage tanks. The gas volumes and pressures were measured daily with the help of installed gauges at these storage tanks. The biogas amount generated

Table 2. Energy outputrecovery of the novel bioenergy plant (mean energy amounts between July 2016 and April 2017).

\begin{tabular}{|c|c|c|c|c|c|c|}
\hline $\begin{array}{l}\text { Monitoring } \\
\text { months }\end{array}$ & $\begin{array}{c}\text { Feedstock-substrate } \\
\text { used } \\
(x 1000 \mathrm{kgs})\end{array}$ & $\begin{array}{c}\text { Mean biogas } \\
\text { recovery } \\
\left(\mathrm{m}^{3} / 1000 \mathrm{~kg} \text { wet }\right. \\
\text { mass })\end{array}$ & $\begin{array}{l}\text { Mean biogas } \\
\text { recovery (m³ } \\
1000 \mathrm{~kg} \text { of VS) }\end{array}$ & $\begin{array}{c}\text { Total biogas } \\
\text { output (m³ } \\
\text { month) }\end{array}$ & $\begin{array}{c}\text { Bioenergy } \\
\text { content }(\mathrm{kJ} / \\
\left.\mathrm{Nm}^{3}\right)^{*} \\
\end{array}$ & $\begin{array}{c}\text { Electrical energy } \\
\text { efficiency (kWh/ } \\
\text { month) }\end{array}$ \\
\hline July 2016 & 100\% CBM 120@4day & 80.53 & 95.86 & 9,663 & $21,329.4$ & 11,493 \\
\hline August 2016 & $\begin{array}{c}100 \% \text { CBM } 120 @ 4 / \\
\text { day }\end{array}$ & 79.33 & 94.44 & 9,520 & $21,329.5$ & 11,322 \\
\hline September2016 & $\begin{array}{c}\text { 75\%CBM:25\%PW } \\
\text { 90:30 @1 + } 3 \text { each/ } \\
\text { day respectively }\end{array}$ & 122.97 & 141.75 & 14,756 & $21,951.8$ & 18,060 \\
\hline October 2016 & $\begin{array}{c}75 \% \text { CBM:25\%PW } \\
\text { 90:30 @1 + } 3 \text { each/ } \\
\text { day respectively }\end{array}$ & 124.82 & 143.90 & 14,978 & $21,951.8$ & 18,334 \\
\hline $\begin{array}{l}\text { November } \\
2016\end{array}$ & $\begin{array}{l}50 \% \mathrm{CBM}: 50 \% \mathrm{PW} \\
\text { 60:60@2 + } 2 \text { each/ } \\
\text { day respectively }\end{array}$ & 112.24 & 125.41 & 13,469 & $20,418.8$ & 15,334 \\
\hline December 2016 & $\begin{array}{c}50 \% \mathrm{CBM}: 50 \% \mathrm{PW} \\
\text { 60:60 @2 + } 2 \text { each/ } \\
\text { day respectively }\end{array}$ & 110.39 & 123.34 & 13,247 & $20,418.8$ & 15,082 \\
\hline January 2017 & $\begin{array}{c}25 \% \text { CBM:75\%PW } \\
30: 90 @ 1+3 \text { each/ } \\
\text { day respectively }\end{array}$ & 94.28 & 102.33 & 11,328 & $20,535.7$ & 12,954 \\
\hline February 2017 & $\begin{array}{l}25 \% \text { CBM:75\%PW } \\
30: 90 @ 1+3 \text { each/ } \\
\text { day respectively }\end{array}$ & 95.73 & 103.77 & 11,488 & $20,535.7$ & 13,154 \\
\hline March 2017 & 100\%PW $120 @ 4 / d a y$ & 92.81 & 97.70 & 11,138 & $20,303.2$ & 13,154 \\
\hline April 2017 & 100\%PW $120 @ 4 /$ day & 91.08 & 95.87 & 10,930 & $20,303.2$ & 12,908 \\
\hline
\end{tabular}

*The average energy content of the biogas generated was calculated relatively to $60 \%$ Vol. methane having a calorific value of $21,521.4 \mathrm{~kJ} / \mathrm{Nm}^{3}$.

**Based on a 150-kW power generator with $38 \%$ (avg.) efficiency. 
Table 3. Recovery of specific biogas and bioenergy determined from the experimental results for various substrate ratios (all data are based on mean duplicates from two months each).

\begin{tabular}{|c|c|c|c|c|c|}
\hline \multirow[b]{2}{*}{$\begin{array}{l}\text { Feedstock } \\
\text { description CBM:PW } \\
\text { (\% Ratio) }\end{array}$} & \multirow[b]{2}{*}{$\begin{array}{l}\text { Biogas recovery ( }{ }^{3} / \\
1000 \mathrm{~kg} \text { wet mass) }\end{array}$} & \multicolumn{2}{|c|}{ Methane recovery } & \multirow[b]{2}{*}{$\begin{array}{c}\% \text { increase in Methane } \\
\text { amount against } 100 \% \text { CBM }\end{array}$} & \multirow[b]{2}{*}{$\begin{array}{l}\text { Electrical energy determined } \\
\text { (kWh/1000 kg wet mass) }\end{array}$} \\
\hline & & $\begin{array}{c}\% \\
\text { Content }\end{array}$ & $\begin{array}{r}\mathrm{m}^{3} / 1000 \mathrm{~kg} \\
\text { wet mass }\end{array}$ & & \\
\hline $100: 00$ & $79.9^{*}$ & 59.1 & $47^{*}$ & - & 95.0 \\
\hline $75: 25$ & $123.9^{*}$ & 62.0 & $77^{*}$ & 61.5 & 151.6 \\
\hline $50: 50$ & $111.3^{*}$ & 54.6 & $61^{*}$ & 29.8 & 126.7 \\
\hline $25: 75$ & 95.0 & 55.2 & 52 & 10.7 & 108.8 \\
\hline $00: 100$ & 91.9 & 58.4 & 53 & 12.8 & 108.6 \\
\hline
\end{tabular}

*Mean values which were found to be significantly different, i.e., $\mathrm{P}<0.05$; Tukey's HSD test.

was measured in $\mathrm{m}^{3}$ per $1,000 \mathrm{~kg}$ of wet mass (Table 2). The percentage composition of the produced biogas and its $\mathrm{CH}_{4}$ content was measured twice a week before and after the scrubbing process by using a gas analyzer GA 2000 (Geo Tech Incorporation, England). The gas analyzer had been 120 calibrated before every reading as per standard procedure. Table 3 depicts this analysis statistically.

\section{Statistical analysis of bioenergy recovery}

Statistical analysis was performed by using the software package PASW Statistics 18. Firstly, the descriptive statistics had been executed to determine the mean values of data, standard deviations, and frequency distributions. The variances in the efficiencies of bioenergy based on various feedstock substrate compositions were tested relatively on a bimonthly pairwise data appraisal methodology. The t-test' and Tukey's HSD test were then employed by fixing the significance level, i.e., $\mathrm{P}=0.05$. MS Excel 2010 was further used for sifting and sorting of data and generating tables and charts.

\section{Results and discussion}

\section{Bioenergy recovery from pure CBM}

Bioenergy recovery in terms of biogas and methane yields against 100\% CBM is shown in Figs. 2 and 3 , respectively. Mean biogas, bio-methane, and electricity yields were calculated as $79.9 \mathrm{~m}^{3} / 1,000 \mathrm{~kg}$, $47 \mathrm{~m}^{3} / 1,000 \mathrm{~kg}$, and $95.0 \mathrm{kWh} / 1,000 \mathrm{~kg}$ (wet mass basis) respectively, during July and August 2015, i.e., months of fermentation in the continuous flow multistage digestion system. The statistical analysis demonstrated that the productivity of biogas and bio-methane generation were significantly 135 different from other feedstock substrates experimented at the plant. The mean biogas productivity/ day $\left(\mathrm{m}^{3} / 1,000 \mathrm{~kg}\right.$ wet mass) against 100\% CBM is shown in Figure 2. On the 17th day of digestion, the peak biogas production rate was observed against $100 \% \mathrm{CBM}$, and this highest biogas recovery rate was $95 \mathrm{~m}^{3} / 1,000 \mathrm{~kg}$ wet mass.

\section{Bioenergy recovery from mixed ratios of CBM and PW}

Three sorts of mixed ratios of CBM and PW were applied: (i) $75 \% \mathrm{CBM}+25 \% \mathrm{PW}$, (ii) $50 \% \mathrm{CBMS}+$ $50 \% \mathrm{PW}$, and (iii) $25 \% \mathrm{CBM}+75 \% \mathrm{PW}$. The respective bioenergy productivities against these three mixed ratios are also portrayed in Figs. 2 and 3. After 2 months of continuous fermentation against each sort of these mixed ratios, i.e., during September-October 2016, November-December 2016, and January-February 2017, the respective mean yields of biogas were calculated as 123.9, 111.3, and $95.0 \mathrm{~m}^{3} / 1,000 \mathrm{~kg}$ wet mass. Whereas the bio-methane generation recovery had been obtained as 77 , 61 , and $52 \mathrm{~m}^{3} / 1,000 \mathrm{~kg}$ wet mass, respectively, and these calculated values significantly exceed the $100 \%$ CBM results. Within 28 days of the digestion process, about 98.9, 96.7, and 91.5\% of the final biogas efficiencies, respectively, had been generated. The mean electrical energy produced against all 


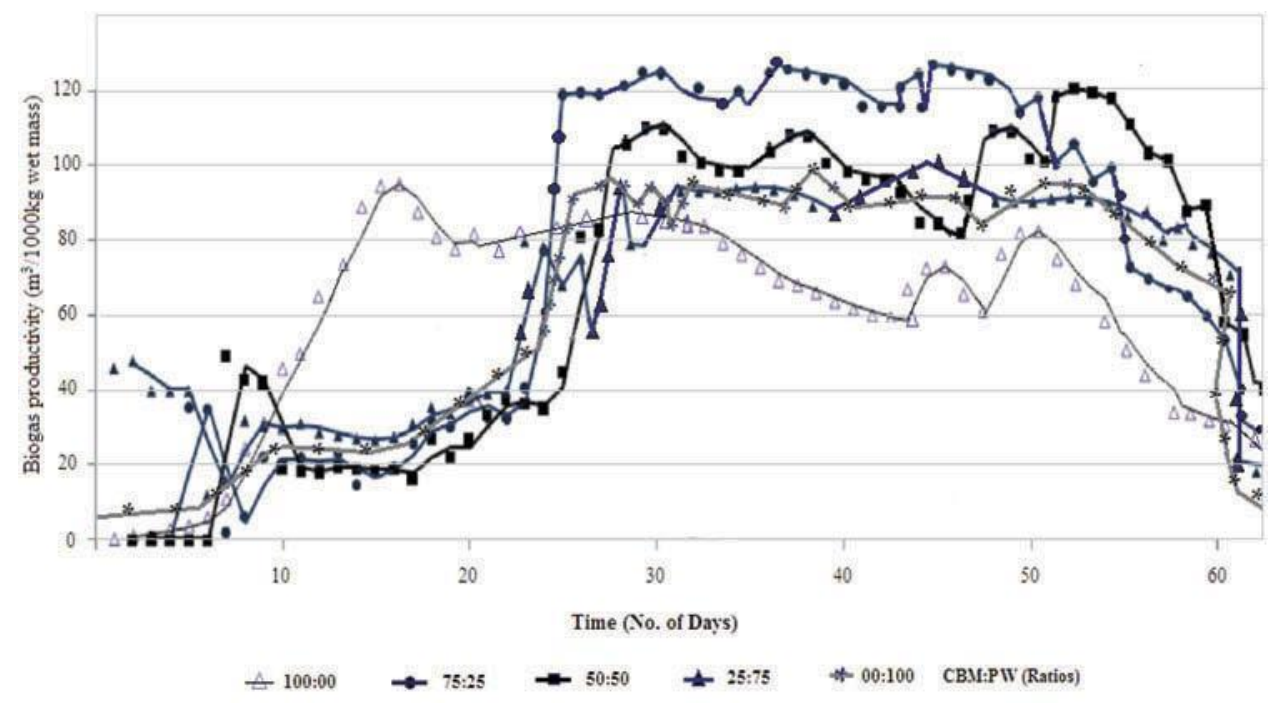

Figure 2. Biogas recovery against various experimented substrate ratios on a novel industrial scale plant.

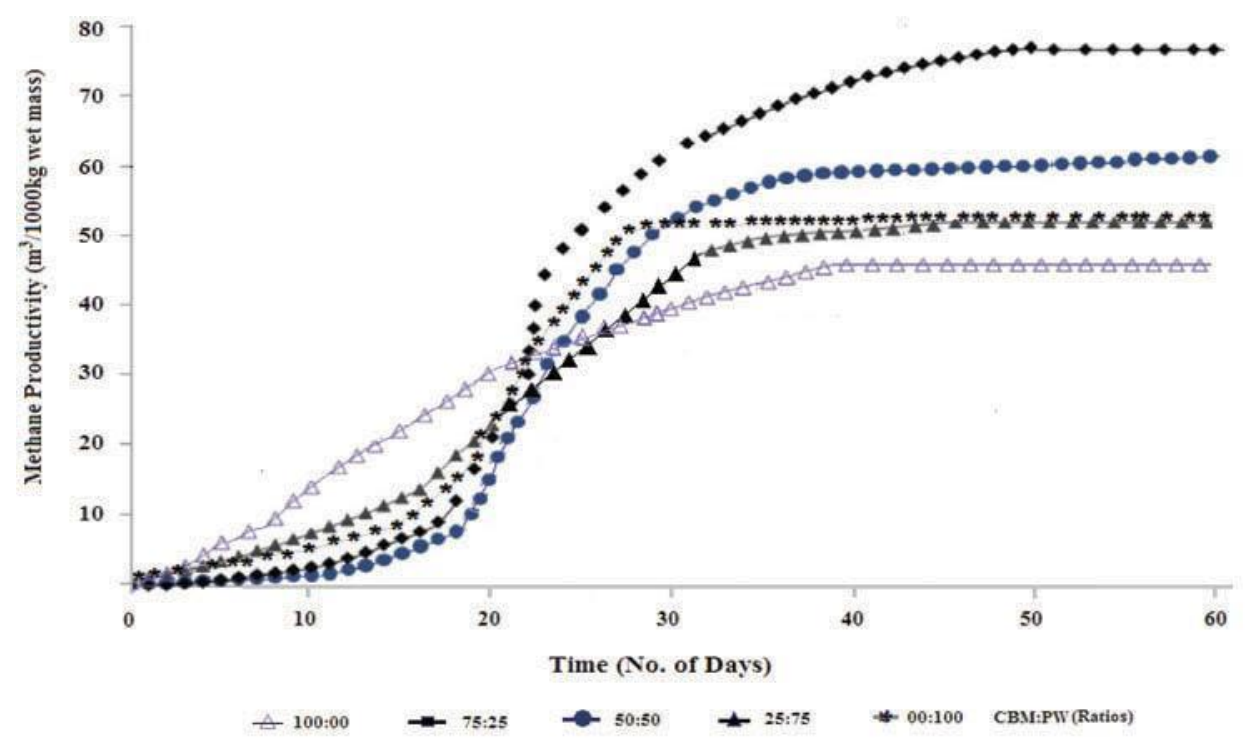

Figure 3. Cumulative bio-methane recovery against various digestion ratios of CBM and PW (on a novel industrial scale plant).

three substrate mixes recorded during the stated months was $151.6,126.7$, and $108.8 \mathrm{kWh} / 1,000 \mathrm{~kg}$ wet mass, respectively.

Furthermore, there was also a significant difference determined among biogas yields of all three substrates mix ratios of CBM+ PW. On the other hand, no significant difference was found among the biogas yields of $100 \% \mathrm{PW}$ and the third mixed ratio of $25 \% \mathrm{CBM}+75 \% \mathrm{PW}$. The biogas recovery/day against these three mixed substrates is depicted in Figure 2, where it was evident that 155 biogas production procedures were similar at all three mixed ratios. However, these went on at a lower rate until the 17th day. It was because of low bacterial concentration, and hence later the subsequent biogas production rates have risen with increased bacterial population and their meta-bolism progression. Between days 28 and 37 of digestion, several peaks of biogas generation rates can 
be seen which are quite unsimilar to the digestion of CBM alone. Hence, it could be derived that codigestion of CBM with PW may diminish the accrual of intermediaries. It leads to a stable performance of the continuous digestion reactor, and as a result better bioenergy generation rates and productivity could be achieved (El-Mashad and Zhang 2010; Rasheed et al. 2016a, 2016b). The results of statistical analysis are also tabulated in Table 3 . There was considerably steady and highest biogas energy recovery for the substrate ratio of $75 \% \mathrm{CBM}$ and $25 \% \mathrm{PW}$ among all feedstock substrates mixtures. Generally, there are larger amounts of bacteria in CBM that caused progressive impacts toward the digestion and infer the higher amounts of bioenergy. Lower CBM:PW ratios lead to lower recovery. It was, hence, established that a greater fraction of CBM substrate in combination with PW caused a synergetic performance with higher and stable yields of bioenergy (Figure 2). Figure 3 depicts that in all feedstock ratios there is complete substrate degradation. The energy system was continuous. With the daily addition of 4,000 $\mathrm{kg}$ of relevant substrates in the reactor, the energy recovery rate gradually stabilized and then remained consistent later on the 28th day of digestion. It was evident against almost all type of feedstock substrates, indicating that the process is reliable. These bioenergy efficiencies are analogous with the results reported earlier (Parawira et al. 2005), where PWs were digested via an acidogenic reactor. Comparable results of a raised energy recovery were obtained by co-digestion of sugar-beet and PW in the initial 10 days, and average digestion period and output results are quite consistent with present study (Kryvoruchko et al. 2009). In the present study, the best results were obtained with 75:25 respective ratio and having $\mathrm{C} / \mathrm{N}=15.5$ (Table 3). These findings are correlated with other literature deliberations (Misi and Forster 2001a, 2001b), whereas the digestion synergism when employing more than one substrate was also confirmed previously (Callaghan et al. 2002).

The corresponding amounts of electrical energy generated in the ratios $100 \% \mathrm{CBM}, 100 \% \mathrm{PW}$, 25\% CBM:75\%, 50\% CBM:50\% PW, and 75\% CBM:25\% PW were calculated as 95.0, 108.6, 108.8, 126.7 , and $151.6 \mathrm{kWh} / 1,000 \mathrm{~kg}$ wet mass, respectively. It depicts the realization potential of the system based on the best available and accessible feedstock. Likewise, their ratios can be adjusted and managed keeping in view the best energy yielding and economically optimal conditions. Similar energy yields with a two-stage AD system for various ratios of sugar beet and PW as feedstock were demonstrated (Parawira et al. 2005).

\section{Bioenergy recovery from pure PW}

The bioenergy efficiencies ( $\mathrm{m}^{3} / 1,000 \mathrm{~kg}$ wet mass) against 100\% PW are presented in Figs. 2 and 3. Bioenergy generation from this substrate was also deliberated for a period of 2 months, i.e., MarchApril 2017. A mean biogas, bio-methane, and electricity yields of $91.9 \mathrm{~m}^{3} / 1,000 \mathrm{~kg}$ wet mass, $53 \mathrm{~m}^{3} / 1,000 \mathrm{~kg}$ wet mass, and $108.6 \mathrm{kWh} / \mathrm{m}^{3} / 1,000 \mathrm{~kg}$ wet mass per month, respectively, were determined during this period. Two peak biogas generation rates were observed as $98.5 \mathrm{~m}^{3}$ and $100 \mathrm{~m}^{3}$ per $1,000 \mathrm{~kg}$ wet mass at 28th and 38th days of digestion, respectively, whereas $94.5 \%$ of the bioenergy recovery had been 195 achieved within 28 days of initial fermentation, against this typical feedstock substrate. Moreover, as compared to $100 \%$ CBM, $75 \%$ CBM:25\% PW, and 50\% CBM:50\% PW, significant differences were found in respect of both biogas and methane generation recovery against $100 \% \mathrm{PW}$ (Table 3 ). However, no significant difference was calculated in biogas and methane yields relative to the substrate mix of $25 \%$ CBM:75\% PW. Liu et al. (2009), Sanaei-Moghadam et al. (2014), and Zhang et al. (2014) also 200 deliberated the similar bioenergy yields based on the $\mathrm{AD}$ of various food waste substrates.

\section{Analytics of COD and VS reduction}

The efficiency of an AD bioenergy reactor can be ascertained via COD and VS measurements, and these were also measured for all the feedstock substrates experimented and employed at this mediumlarge industrial bioenergy plant. These were observed and analyzed twice, i.e., at the 205 commencement and at the culmination points during each 2-month period of utilization of each 
type of feedstock substrate as per Table 1 and Figure 4. As such the calculated aggregates of COD reduction ranged from $56.9 \%$, i.e., the lowest value measured for $25 \% \mathrm{CBM}: 75 \% \mathrm{PW}$, to $70.6 \%$ as the highest value for $100 \%$ CBM. The average COD reduction against all feedstock substrates was about $60.3 \%$ although this percentage decreased with the decreased addition of co-substrate, i.e., potato waste. The highest COD reduction occurred for the 75\% CBM:25\% PW mix, where also the highest energy yield and energy productivity were obtained. Similar COD removal efficiencies of 53-70\% were reported (Sanaei-Moghadam et al. 2014) for the co-digestion of press water and food waste. Other studies (Borui, Sun, and Wang 2013; Safari et al. 2011) regarding AD treatment of MSW leachate reported COD reductions in the range of 32-96\% and the lower COD reductions were correlated to low organic matter loading rates. The average volatile solids eradication was deliberated as 53 and $55.6 \%$ for the substrates of $100 \% \mathrm{CBM}$ and $100 \% \mathrm{PW}$, respectively. Whereas the average VS eradications in other feedstock mixtures having co-substrates were found increasing as 56.4, 62.6, and $69.5 \%$ against 25\% CBM:75\%, 50\% CBM:50\% PW, and 75\% CBM:25\% PW, respectively (Figure 4).

\section{Error and regression analysis}

Table 4 portrays the error analysis of the presented, i.e., bioenergy recovery efficiency versus the rate of eradication of VS on this typical industrial scale AD plant, where MAD was found as 1.12 which referred to be an adequate error value for such energy efficiency forecasts. Likewise, MSE was the calculated average of the squared forecast error and its value here, i.e., 1.5, shows that expected and predicted values have been quite close, as such data are reliable. Moreover, MAPE value, 0.02 as represented in Table 4, further strengthens the argument, as this value is easier to interpret and a smaller MAPE value indicates that the data depictions and analysis regarding bioenergy productivity have been accurate. Lay, Lee, and Noike (1999), Akkaya et al (2015), and Rahman et al. (2017) also presented similar data error analysis for their studies on hydrogen production from organic fraction of MSW; biogas generation from a UASB reactor via multiple regression model; and optimal ratio for anaerobic co-digestion of poultry droppings and lignocellulosic-rich substrates, respectively.

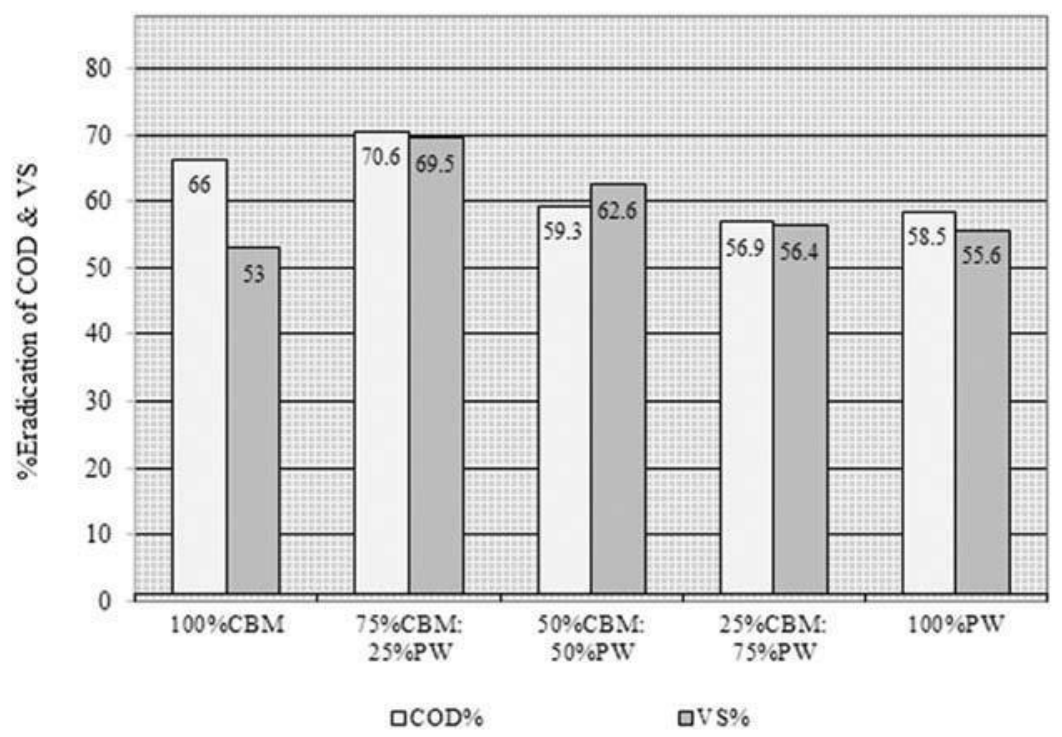

Figure 4. Destruction rates of COD and VS against various digestion ratios of CBM and PW (on a novel industrial scale plant). 
Table 4. Error Analysis: Bioenergy recovery v/s eradication of VS on industrial scale plant.

\begin{tabular}{|c|c|c|c|c|c|c|c|}
\hline Month & Biogas recovery $\left(\mathrm{m}^{3} / 1000 \mathrm{~kg} \mathrm{VS}\right)$ & $\%$ VS eradication & Forecast & Error & ABS (Error) & Squared Error & Percent Error \\
\hline July 2016 & 94.4 & 54.0 & 53.52 & 0.58 & 0.58 & 0.33 & 0.01 \\
\hline Aug. 2016 & 96.0 & 52.0 & 54.05 & -2.05 & 2.05 & 4.21 & 0.04 \\
\hline Sept. 2016 & 96.0 & 55.0 & 54.05 & 0.95 & 0.95 & 0.90 & 0.02 \\
\hline Oct. 2016 & 98.0 & 56.0 & 54.71 & 1.29 & 1.29 & 1.66 & 0.02 \\
\hline Nov. 2016 & 102.0 & 55.0 & 56.03 & -1.43 & 1.43 & 2.05 & 0.03 \\
\hline Dec. 2016 & 104.0 & 58.0 & 56.69 & 1.31 & 1.31 & 1.71 & 0.02 \\
\hline Jan. 2017 & 123,0 & 61.0 & 62.97 & -1.57 & 1.57 & 2.45 & 0.03 \\
\hline Feb. 2017 & 125.0 & 64.0 & 63.63 & 0.37 & 0.37 & 0.14 & 0.01 \\
\hline March 2017 & 142,0 & 69.0 & 69.24 & -0.54 & 0.54 & 0.29 & 0.01 \\
\hline \multirow[t]{2}{*}{ April 2017} & 144.0 & 71.0 & 69.90 & 1.10 & 1.10 & 1.21 & 0.02 \\
\hline & & & & & 1.12MAD* & $1.50 \mathrm{MSE}^{*}$ & 0.02 MAPE* \\
\hline
\end{tabular}

${ }^{\star} \mathrm{MAD}=$ mean absolute deviation; $\mathrm{MSE}=$ mean squared error and MAPE = mean absolute percent error.

The correlation of VS eradication and biogas yield was established using 'linear regression analysis' and had been plotted as shown in Figure 5. Subsequent linear regression equation and the enormous value of $\mathrm{R}^{2}$, correlation coefficient, directed about a significant and positive correlation among the rate of VS eradication and biogas yield (Figure 5), which established that higher biogas efficiencies were dependent upon higher OM degradation and VS eradication rates. In an identical investigation by $\mathrm{Li}$, Chen, and $\mathrm{Li}$ (2010), authors also established a linear regression correlation among rates of biogas productivity, total solids, and volatile solids. In a similar regression analysis by Akkaya et al (2015), the best correlation coefficients had been established and the relevant study, therefore, could predict accurate biogas productivity.

\section{Conclusion}

This article presented and reviewed the consistent functioning of a novel medium industrial scale bioenergy plant, in terms of energy recovery and productivity. Biogas yield and subsequent electricity

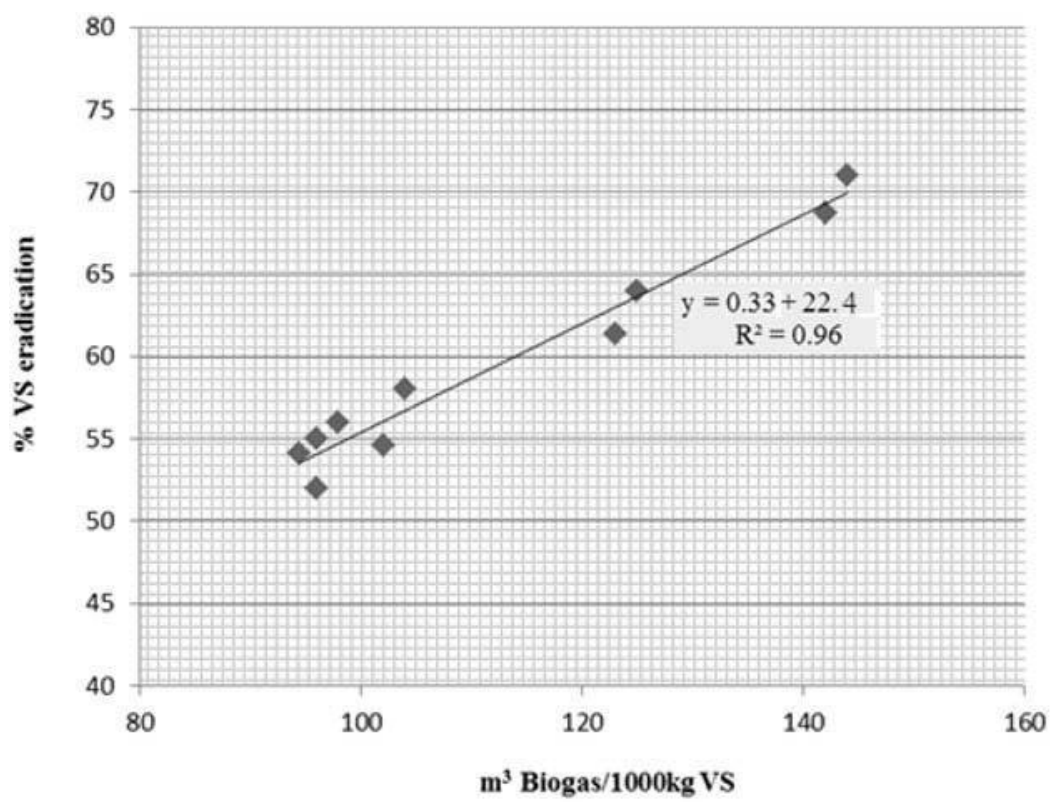

Figure 5. Correlation among bioenergy recovery and eradication of VS on an industrial scale plant. 
efficiency could be optimally managed and enhanced based on available substrates in a typical regional scenario. The long-duration experimental results revealed that feedstock substrate consisting of $75 \%$ CBM plus $25 \%$ PW produced the best energy yields, i.e., $124 \quad \mathrm{~m}^{3}$ biogas, $77 \mathrm{~m}^{3}$ biomethane, and $152 \mathrm{kWh}$ electricity per $1,000 \mathrm{~kg}$ of wet mass, respectively. The system performance and recovery can be further enhanced by a more direct corrective action if a rapid high-tech online quantitative monitoring system could be used.

\section{ORCID}

Rizwan Rasheed (D) http://orcid.org/0000-0002-5441-7376

Sajid Rashid Ahmad D http://orcid.org/0000-0003-0122-472X

\section{References}

Abouelenien, F., Y. Namba, M. R. Kosseva, N. Nishio, and Y. Nakashimada. 2014. Enhancement of methane production from co-digestion of chicken manure with agricultural wastes. Bioresource Technology 159:80-87. doi:10.1016/j.biortech.2014.02.050.

Agyeman, F. O., and W. Tao. 2014. Anaerobic co-digestion of food waste and dairy manure: Effects of food waste particle size and organic loading rate. Journal of Environmental Management 133:268-74. doi:10.1016/j. jenvman.2013.12.016.

Akbulut, A. 2012. Techno-economic analysis of electricity and heat generation from farm-scale biogas plant: Çiçekdağ1 case study. Energy 44(1):381-90. doi:10.1016/j.energy.2012.06.017.

Akkaya, E., A. Demir, and G. Varank. 2015. Estimation of biogas generation from a uasb reactor via multiple regression model. International Journal of Green Energy 12(2):185-89. doi:10.1080/15435075.2011.651754.

Alatriste-Mondragón, F., P. Samar, H. H. Cox, B. K. Ahring, and R. Iranpour. 2006. Anaerobic codigestion of

municipal, farm, and industrial organic wastes: A survey of recent literature. Water Environment Research : A Research Publication of the Water Environment Federation 78(6):607-36.

Apha, A. 1998. WPCF, 1998.Standard Methods for the Examination of Water and Wastewater (20).

Astals, S., V. Nolla-Ardèvol, and J. Mata-Alvarez. 2012. Anaerobic co-digestion of pig manure and crude glycerol at mesophilic conditions: Biogas and digestate. Bioresource Technology 110:63-70. doi:10.1016/j.biortech.2012.01.080. 270

Baeyens, J., L. Appels, L. Peng, and R. Dewil. 2016. The production of bio-energy by microbial (biogas through anaerobic digestion) or thermal (pyrolysis) processes. Renewable Energy: An International Journal 96:1055-1055. doi:10.1016/j.renene.2016.06.012.

Borui, F. U., Y. Sun, and Y. X. Wang. 2013. Construction of biogas fermentation system based on feedstock of potato residue. Journal of Northeast Agricultural University 44(11):102-06.

Budzianowski, W. M. 2012. Sustainable biogas energy in Poland: Prospects and challenges. Renewable and Sustainable Energy Reviews 16(1):342-49. doi:10.1016/j.rser.2011.07.161.

Callaghan, F. J., D. A. J. Wase, K. Thayanithy, and C. F. Forster. 2002. Continuous co-digestion of cattle slurry with fruit and vegetable wastes and chicken manure. Biomass and Bioenergy 22(1):71-77. doi:10.1016/S0961-9534(01) 00057-5.

Cavinato, C., F. Fatone, D. Bolzonella, and P. Pavan. 2010. Thermophilic anaerobic co-digestion of cattle manure with agro-wastes and energy crops: Comparison of pilot and full scale experiences. Bioresource Technology 101(2):54550. doi:10.1016/j.biortech.2009.08.043.

Comino, E., V. A. Riggio, and M. Rosso. 2012. Biogas production by anaerobic co-digestion of cattle slurry and cheese whey. Bioresource Technology 114:46-53. doi:10.1016/j.biortech.2012.02.090.

Cuetos, M. J., C. Fernández, X. Gómez, and A. Morán. 2011. Anaerobic co-digestion of swine manure with energy crop residues. Biotechnology and Bioprocess Engineering 16(5):1044-52. doi:10.1007/s12257-011-0117-4. Deublein, D., and A. Steinhauser. 2011. Biogas from waste and renewable resources: An introduction. Wiley-VCH. ECOFYS. 2005. Planning and installing bioenergy systems: A guide for installers, architects and engineers. Vol. 1. Earthscan.

El-Mashad, H. M., and R. Zhang. 2010. Biogas production from co-digestion of dairy manure and food waste. Bioresource Technology 101(11):4021-28. doi:10.1016/j.biortech.2010.01.027.

Esposito, G., L. Frunzo, A. Giordano, F. Liotta, A. Panico, and F. Pirozzi. 2012. Anaerobic co-digestion of organic wastes. Reviews in Environmental Science and Bio/Technology 11(4):325-41. doi:10.1007/s11157-012-9277-8. Fitamo, T., A. Boldrin, K. Boe, I. Angelidaki, and C. Scheutz. 2016. Co-digestion of food and garden waste with mixed sludge from wastewater treatment in continuously stirred tank reactors. Bioresource Technology 206:245-54. doi:10.1016/j.biortech.2016.01.085. 
Gebrezgabher, S. A., M. P. Meuwissen, B. A. Prins, and A. G. O. Lansink. 2010. Economic analysis of anaerobic digestion-A case of Green power biogas plant in The Netherlands. NJAS-Wageningen Journal of Life Sciences 57 (2):109-15. doi:10.1016/j.njas.2009.07.006.

Gunaseelan, V. N. 2004. Biochemical methane potential of fruits and vegetable solid waste feedstocks. Biomass and Bioenergy 26(4):389-99. doi:10.1016/j.biombioe.2003.08.006.

Hinken, L., I. Urban, E. Haun, D. Weichgrebe, and K. H. Rosenwinkel. 2008. The valuation of malnutrition in the mono-digestion of maize silage by anaerobic batch tests. Water Science and Technology : a Journal of the International Association on Water Pollution Research 58(7):1453-59. doi:10.2166/wst.2008.491.

Hosseini, S. E., A. M. Andwari, M. A. Wahid, and G. Bagheri. 2013. A review on green energy potentials in Iran. Renewable and Sustainable Energy Reviews 27:533-45. doi:10.1016/j.rser.2013.07.015.

Hosseini, S. E., and M. A. Wahid. 2013. Feasibility study of biogas production and utilization as a source of renewable energy in Malaysia. Renewable and Sustainable Energy Reviews 19:454-62. doi:10.1016/j.rser.2012.11.008.

Kothari, R., A. K. Pandey, S. Kumar, V. V. Tyagi, and S. K. Tyagi. 2014. Different aspects of dry anaerobic digestion for bio-energy: An overview. Renewable and Sustainable Energy Reviews 39:174-95. doi:10.1016/j.rser.2014.07.011.

Kryvoruchko, V., A. Machmüller, V. Bodiroza, B. Amon, and T. Amon. 2009. Anaerobic digestion of by-products of sugar beet and starch potato processing. Biomass and Bioenergy 33(4):620-27. doi:10.1016/j. biombioe.2008.10.003.

Lay, J. J., Y. J. Lee, and T. Noike. 1999. Feasibility of biological hydrogen production from organic fraction of municipal solid waste. Water Research 33(11):2579-86. doi:10.1016/S0043-1354(98)00483-7.

Li, C., Y. Liao, X. Wen, Y. Wang, and F. Yang. 2015. The development and countermeasures of household biogas in northwest grain for green project areas of China. Renewable and Sustainable Energy Reviews 44:835-46. doi:10.1016/j.rser.2015.01.027.

Li, R., S. Chen, and X. Li. 2010. Biogas production from anaerobic co-digestion of food waste with dairy manure in a two-phase digestion system. Applied Biochemistry and Biotechnology 160(2):643-54. doi:10.1007/s12010-009-8533$\mathrm{z}$.

Liu, G., R. Zhang, H. M. El-Mashad, and R. Dong. 2009. Effect of feed to inoculum ratios on biogas yields of food and green wastes. Bioresource Technology 100(21):5103-08. doi:10.1016/j.biortech.2009.03.081.

Misi, S. N., and C. F. Forster. 2001a. Batch co-digestion of two-component mixtures of agro-wastes. Process Safety and Environmental Protection 79(6):365-71. doi:10.1205/095758201753373140.

Misi, S. N., and C. F. Forster. 2001b. Batch co-digestion of multi-component agro-wastes. Bioresource Technology 80 (1):19-28. doi:10.1016/S0960-8524(01)00078-5.

Moody, L. B., R. T. Burns, G. Bishop, S. T. Sell, and R. Spajic. 2011. Using biochemical methane potential assays to aid in co-substrate selection for co-digestion. Applied Engineering in Agriculture 27(3):433-39. doi:10.13031/ 2013.37068.

Nkemka, V. N., and M. Murto. 2010. Evaluation of biogas production from seaweed in batch tests and in UASB reactors combined with the removal of heavy metals. Journal of Environmental Management 91(7):1573-79. doi:10.1016/j.jenvman.2010.03.004.

Parawira, W., M. Murto, J. S. Read, and B. Mattiasson. 2005. Profile of hydrolases and biogas production during twostage mesophilic anaerobic digestion of solid potato waste. Process Biochemistry 40(9):2945-52. doi:10.1016/j. procbio.2005.01.010.

Park, S., and Y. Li. 2012. Evaluation of methane production and macronutrient degradation in the anaerobic codigestion of algae biomass residue and lipid waste. Bioresource Technology 111:42-48. doi:10.1016/j. biortech.2012.01.160.

Pobeheim, H., B. Munk, J. Johansson, and G. M. Guebitz. 2010. Influence of trace elements on methane formation from a synthetic model substrate for maize silage. Bioresource Technology 101(2):836-39. doi:10.1016/j. biortech.2009.08.076.

Rahman, M. A., H. B. Møller, C. K. Saha, M. M. Alam, R. Wahid, and L. Feng. 2017. Optimal ratio for anaerobic codigestion of poultry droppings and lignocellulosic-rich substrates for enhanced biogas production. Energy for Sustainable Development 39:59-66. doi:10.1016/j.esd.2017.04.004.

Rasheed, R., N. Khan, A. Yasar, Y. Su, and A. B. Tabinda. 2016a. Design and cost-benefit analysis of a novel anaerobic industrial bioenergy plant in Pakistan. Renewable Energy 90:242-47. doi:10.1016/j.renene.2016.01.008.

Rasheed, R., A. Yasar, A. B. Tabinda, N. Khan, Y. Su, and M. Afzaal. 2016b. Techno-economic impacts of innovative commercial-industrial bioenergy plant in Pakistan. Pakistan Journal of Agricultural Sciences 53(3):647-52. doi:10.21162/PAKJAS/16.4782.

Safari, E., M. Jalili Ghazizade, A. Shokouh, and G. R. Nabi Bidhendi. 2011. Anaerobic removal of COD from high strength fresh and partially stabilized leachates and application of multi stage kinetic model. International Journal of Environmental Research 5(2):255-70.

Sanaei-Moghadam, A., M. H. Abbaspour-Fard, H. Aghel, M. H. Aghkhani, and J. Abedini-Torghabeh. 2014. 355 Enhancement of biogas production by co-digestion of potato pulp with cow manure in a CSTR system. Applied Biochemistry and Biotechnology 173(7):1858-69. doi:10.1007/s12010-014-0972-5. 
Sawasdee, V., an Pisutpaisal. 2014. Feasibility of biogas production from Napier grass. Energy Procedia 61:122933. doi:10.1016/j.egypro.2014.11.1064.

Shah, F. A., Q. Mahmood, N. Rashid, A. Pervez, I. A. Raja, and M. M. Shah. 2015. Co-digestion, pretreatment and digester design for enhanced methanogenesis. Renewable and Sustainable Energy Reviews 42:627-42. doi:10.1016/j. rser.2014.10.053.

Sittijunda, S. 2015. Biogas production from hydrolysate napier grass by co-digestion with slaughterhouse wastewater using anaerobic mixed cultures. Asia-Pacific Journal of Science and Technology 20(3):323-36.

Song, Z., C. Zhang, G. Yang, Y. Feng, G. Ren, and X. Han. 2014. Comparison of biogas development from households and medium and large-scale biogas plants in rural China. Renewable and Sustainable Energy Reviews 33:204-13. doi:10.1016/j.rser.2014.01.084.

Walla, C., and W. Schneeberger. 2008. The optimal size for biogas plants. Biomass and Bioenergy 32(6):551-57. doi:10.1016/j.biombioe.2007.11.009.

Wang, X., G. Yang, F. Li, Y. Feng, and G. Ren. 2013b. Response surface optimization of methane potentials in anaerobic co-digestion of multiple substrates: Dairy, chicken manure and wheat straw. Waste Management \& Research 31(1):60-66. doi:10.1177/0734242X12468197.

Wang, X., G. Yang, F. Li, Y. Feng, G. Ren, and X. Han. 2013a. Evaluation of two statistical methods for optimizing the feeding composition in anaerobic co-digestion: Mixture design and central composite design. Bioresource Technology 131:172-78. doi:10.1016/j.biortech.2012.12.174.

Weiland, P. 2010. Biogas production: Current state and perspectives. Applied Microbiology and Biotechnology 85 (4):849-60. doi:10.1007/s00253-009-2246-7.

Yang, J., and B. Chen. 2014. Emergy analysis of a biogas-linked agricultural system in rural China-A case study in Gongcheng Yao Autonomous County. Applied Energy 118:173-82. doi:10.1016/j.apenergy.2013.12.038.

Zhang, C., H. Su, J. Baeyens, and T. Tan. 2014. Reviewing the anaerobic digestion of food waste for biogas production. Renewable and Sustainable Energy Reviews 38:383-92. doi:10.1016/j.rser.2014.05.038.

Zhang, C., G. Xiao, L. Peng, H. Su, and T. Tan. 2013a. The anaerobic co-digestion of food waste and cattle manure. Bioresource Technology 129:170-76. doi:10.1016/j.biortech.2012.10.138.

Zhang, R., H. M. El-Mashad, K. Hartman, F. Wang, G. Liu, C. Choate, and P. Gamble. 2007. Characterization of food waste as feedstock for anaerobic digestion. Bioresource Technology 98(4):929-35. doi:10.1016/j.biortech.2006.02.039.

Zhang, T., L. Liu, Z. Song, G. Ren, Y. Feng, X. Han, and G. Yang. 2013b. Biogas production by co-digestion of goat manure with three crop residues. PloS One 8(6):e66845. doi:10.1371/journal.pone.0066845. 